\title{
ARTIGOS
}

\section{OPTIMIZATION OF GREEN-BUILDING DESIGN PROCESSES - CASE STUDY}

\author{
Alessandro Orsi, Ignacio Guillén Guillamón. \\ Polytechnic University of Valencia (Spain)
}

KEYWORDS:

Green-building; project management; design process; optimization; LEAN; process waste; sustainability.

\begin{abstract}
The development of a green-building project following a specific reference standard such as LEED, brings new conditions and restrains for all subjects involved in the process. Such changes affect technicians, owners, bureaucracy and also the management tasks either during design or construction phases. Within this scope, project management plays a key role for the optimization of the design-project development. This research analyzes the design process of a single case-study project from the project management perspective, taking into consideration all the activities that negatively affected the project design development. The project selected for the scope of the research is a new school complex located in Northern Italy currently pursuing the LEED Gold certification with a project cost of 13,2 million Euros. A new methodology was created in order to analyze the project and evaluate the effects of detected project-management issues under three different points of view: costs, time and building sustainability. Such "issues" were identified by researchers on the basis of the LEAN-definition of "waste". The scope of the research is to develop and test a methodology for the optimization of the project management processes during the development of a LEED building design in Europe through the detection and evaluation of process wastes. The results showed that project management issues related to green-building tasks affect considerably the cost, schedule and sustainability of the project design and vice versa, the accuracy of the project management tasks affect the sustainability features of the final building design.
\end{abstract}




\section{INTRODUCTION}

The importance of sustainability within the construction business has been increasing dramatically during the last decades [1] (P. Hansford et al. - 2013) and, as some research studies point out, "an increased emphasis must be placed on the processes and competencies required to deliver high-performance buildings" [2] (Horman et al. - 2006). Currently, many researchers focus on understanding different aspects of delivering green-building projects in order to minimize waste, maximize value, and reduce cost. During the last years several research studies analyzed different project management issues related to green-building developments. Their main goal is to optimize the project management process for developing green-building projects focusing on different aspects, such as, counterfactual analysis [3] (Klotz et al. - 2009), LEAN processes [4] (Lapinski et al. - 2006), piloting evaluation metrics [5] (Korkmaz et al. - 2010).

As Lenfle points out in a recent study, "the links between studies devoted to project management and innovation management are complex and marked by a relative lack of communication between the two fields" [6] (Lenfle2008). Moreover, during the last years project management practice has evolved into a business process and got detached from the practical aspects of the job tasks [7] (Kerzer - 2013). The scope of this research is to develop a practical approach for analyzing project management processes intended as hands-on management tasks easily understandable and applicable by technicians in real projects. Following the guidelines of Russel-Smith [8] (Russel-Smith et al. - 2015) researchers aim to provide support resources that will allow designers to iteratively improve and re-engineer the processes reducing the impact of the building design from initial to final design.

The concept of sustainability has been standardized internationally through the implementation of different protocols but the majority of the research studies have been developed on the basis of common project management processes that refer to the United States construction industry [9] (Lopez \& Sánchez - 2010). Recently, sustainability has become a key aspect of the construction field [10] (Enache, Pommer \& Horman - 2009) and this includes also project management. However, despite their demonstrated benefits, green buildings are not yet perceived as attractive projects because most people associate green features with expensive technologies that add cost [11] (Castro-Lacouture et al.).
Case studies, interviews and data collection used for the majority of the research articles take into consideration the average Anglo-American construction process. In other countries and more specifically within the European Union the construction and project management process is substantially different. More subjects are involved and local laws establish new hierarchies within the whole construction and project development process [12] (Guy \& Moore - 2005).

Within the US construction and project delivery process for design-bid-built projects, designers and contractors work almost independently following a two -party contract. However, within the European system four different parties are involved at the same time and occasionally each of them take over certain project management tasks. As a result the project management process is more fragmented and difficult to analyze. Figure 1 and 2 shows the different schemes representing the contractual linear dependencies between subjects involved within a design-bid-built common process.

Figure 1 and 2 - Representation of the contractual dependencies between subjects involved in the Design-Bid-Built European and U.S. construction process.
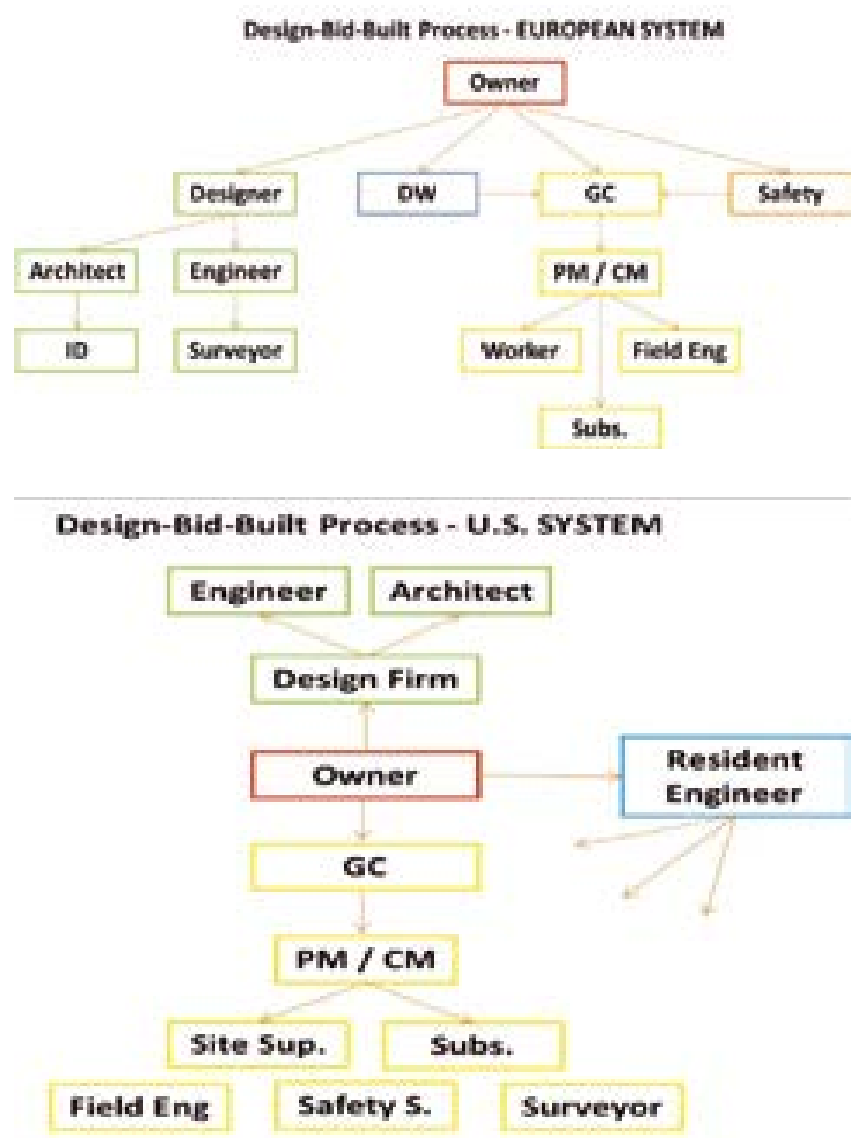

Fonte - Autors 
"The scope of this research is to analyze the potential project management issues within the design process of an average green building project developed within the European Community.

The whole research is based on a real case-study project and has been carried out through three different stages:

- Data collection and process illustration;

- Process Analysis and detection of project-management issues; - Estimate of the impact of project-management issues on project costs, schedule and sustainability.

The project selected for the case-study is a new Middle School Complex located in Trento, Northern Italy, certified under the LEED for Schools 2007, with a total budget of approximately 13,2 Million Euros and a total gross square footprint of 6.000 square meters. The choice of this project as single-case study project was made on the basis of the following statements:

-Direct access to project information and contact with all technicians involved in the project;

-Simultaneity between research and project design development;

-Project sustainability referring to LEED credits as benchmark for evaluation.

The choice of a single case-study project helped researchers testing a new methodology for the analysis of the project management issues in green-building developments. The intent is to develop a deep hands-on analysis where specific problems related to specific activities and circumstances could be identified and, possibly, prevented.

\subsection{Deliverables and potential benefits of the research}

The present research has two main outputs. First, the validation of the new methodology developed by researchers to analyze sustainability-related issues within the development of a European green-building design project. Secondly, the evaluation of the impact of the sustainability-related issues within the whole design development in terms of costs, time and sustainability features. The scope of the research could be summarized as: "the optimization of the project management process for the development of a LEED building design in Europe through the detection and evaluation of process wastes".

The methodology is described step by step proposing a new point of view for future researchers, the impact of sustainability-related issues will be globally estimated in terms of Euros, extra work days and lost LEED points. Once the methodology will be further developed researchers aim to improve it and use it to analyze and evaluate other green-building projects within the European Union.

\section{METHODOLOGY}

Data collection was carried out using two different methods: project documentation analysis and personal interviews. The data collection started with the late design phase of the project which allowed researchers to acquire information first-hand from personal interviews with technicians and public entities. Researchers waited for the last building design phase, called "executive design", to acquire all project information in order to have a global view of the process and better evaluating the effect of each issue on the design process development.

Project documentation such as technical reports and drawings was provided by the project owner and included all information related to each step, activity and event affecting the project design phase from the early preliminary design stage until the final executive phase. At the end of th is phase researchers developed a bar chart listing all main activities of the project design development process.

Interviews were made by researchers personally to technicians and personnel involved in the project. The interview process was standardized by using a common procedure for all interviewees. Each subject recognized all the problems they encountered during the design development and indicated them in the list of project activities developed before. The concept of "problem" was defined on the basis of the "waste" definition provided within the LEAN management system. In simple words, any type of activity performed during the process that in spite of consuming resources doesn't bring added value to the final product [13] (J. Liker - 2003). Out of the seven types of waste identified for an industrial LEAN process [13] (J. Liker - 2003) for the purpose of this research only five types of problems were considered: waiting (delays in the process), transportation (unnecessary movement of people or materials), extra-processing (re-manufacturing and activity reiteration), costs (unforeseen expenses for project-related activities), defects (intended as project weaknesses that didn't allow the team to reach the expected level of sustainability within the LEED certification). Only problems directly associated with the project structure were considered for the current analysis. Following the definition of Whelton \& Ballard, only well-defined and ill structured problems were taken into consideration for the purpose of this research [14] (Whelton \& Ballard - 2002). 
"Problems" as identified by all subjects were in fact the consequence of the structural issues (or project management issues) researchers were interested in. Therefore problems initially identified by technicians were labelled and gathered together in several "categories of issues" which represent the real project management problems researchers wanted to analyze. From now on in the present article the word "problem" will be referred to the issue categories mentioned above if not differently specified. The categories of issues identified for the purpose of the present research are listed below:

-Misunderstanding of Commissioning Authority's tasks and process;

-Lack of appropriate clauses in bid documentation;

-Systematic cuts to budget due to change-orders and delays;

-Lack of knowledge about energy modelling role and process; -Lack of project management role supervising the whole project.

Some of the problems were related to single activities, others to a whole set of project tasks. The impact of the " $n$ " problem on the whole project completion was estimated as the sum of the impact of that specific problem on each activity it affected in the following three dimensions: time, costs and sustainability.

Consequences of problems on project schedule were analyzed and evaluated with the use of a project management software, Microsoft Project. The list of activities was used to create a Gantt diagram for the whole project. Problems were accounted as activities and identified with different colors depending on their relationship with time, costs or sustainability. For the purpose of the present research only issues related to green-building activities were taken into consideration. Duration of each activity was defined on the basis of the data collected from the project documentation.

Cost-related issues were estimated using data collected from two different sources, cash-flow volume documented by project files and cost information acquired during the different interviews with technicians. Cost-related information for each problem were provided as Euros amount or as number of extra hours spent to solve the problem. In case of the hourly-based information researchers estimate the corresponding Euros amount multiply the number of hours by the average hourly salary for a middle-range professional technician with a short-term consulting contract in Italy [15] (II Sole 24 Ore - 2015). All categories of issues previously identified were used to develop the cost analysis. The cost of each problem resulted from the sum of the extra costs of all activities affected by that specific problem. The Gantt diagram was used to link each problem to groups of project tasks, total problem costs were then estimated afterwards using simple Excel sheets.

Sustainability-related issues were analyzed on the basis of the LEED protocol score. Prior to project start the design team performed a kick-off meeting with all subjects involved in the project and filled up a LEED checklist where all credits considered "potentially achievable" were listed taking the whole LEED credit list as an optimum reference. During the project development some of those credits were not achieved because of project management issues and researchers focused on those credits the project could not obtain due to sustainability-related project management issues. The problem representation procedure had to go through a iterative process in order to have a set of results that could be graphically understandable and summarize the results. Different filters were applied in order to eliminate unnecessary information and bring only the most important to the eyes of the reader.

\section{RESULTS}

Information resulting from the present research were divided into three groups respectively related to three types of waste: delays in project completion, money spent over budget and misachievement of sustainability points.

Total amount of delays caused by sustainability related problems cited above were estimated on the basis of the bar-chart results developed using Microsoft Project. Within the bar chart, sustainability-related problem previously identified by researchers were accounted as normal activities with predecessors and successors and their duration was estimated on the basis of the data previously collected through project documentation and interviews. Critical path was then calculated on the basis of the scheduling concepts [16] (Harris, R.B. - 1978) along with free-float and total-float of each activity. The duration of all sustainability-related problems included on the project critical path were accounted for the total project delay. The duration of all sustainability-related problems of the whole project bar chart were accounted for the total loss of time. Results of this double accountant operation are listed on a Figure 4 below which represents on the $X$ axis the type of problem and on the $Y$ axis the results obtained: total project delay and total loss of time. Figure 3 represent a snapshot of the bar chart cited above. 
Figure 3 - Snapshot of the project Gantt diagram showing problems (red), problem-related activities (orange), sustainability-related activities (green).

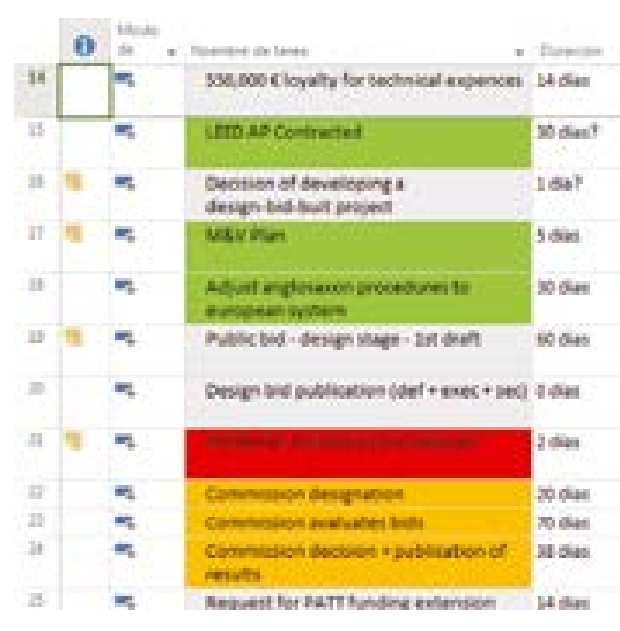

Quantities resulting from cost analysis were sorted out in two different categories: direct costs and indirect costs. The term "direct costs" refers to all expenses, caused by the sustainability-related problems that the owner had to bear in addition to the original project budget in order to complete the design process. The term "indirect costs" researchers identified two types of quantities:

- All additional costs caused by the sustainability-related problems that technicians involved in the project had to bear with no additional compensation to their professional fee.

- All additional costs caused by the effects of the sustainability -related problems which affected third parties and later project development phases.

All costs were documented through interviews and project documentation and are summarized in Figure 4 below showing two sections, one for the direct costs and

Figure 4 - table summarizing the direct and indirect costs generated by all problem categories and related activities. another for the indirect costs.

On each table the horizontal axis summarizes the problem category, the vertical axis the problem-related activities and the numbers represent the cost in Euros that each specific activity had in order to solve each specific problem.

Results for sustainability-related points were estimated on the basis of the LEED protocol. Taking the whole possible score identified at the beginning of the project as a reference, researchers focused on all LEED points that finally couldn't be achieved due to project management issues related with sustainability (which are included in the problem category list cited above). Below are summarized the research results for the sustainability and cost-related aspects divided by problem categories previously identified.

- Misunderstanding of Commissioning Authority's (CxA) tasks and process. Project designers and owner

\begin{tabular}{|c|c|c|c|c|c|c|}
\hline \multicolumn{7}{|c|}{ Cost ANuL rys idiect Cont? } \\
\hline 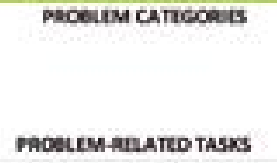 & $\begin{array}{l}\text { Commindoning } \\
\text { Avithoritytanls } \\
\text { A procen }\end{array}$ & $\begin{array}{l}\text { No appropriate } \\
\text { tlawses in bid } \\
\text { excumentarion }\end{array}$ & $\begin{array}{l}\text { Lack of project } \\
\text { miniper for } \\
\text { whole preject }\end{array}$ & $\begin{array}{l}\text { Systemicke cuts } \\
\text { to project } \\
\text { budent }\end{array}$ & $\begin{array}{l}\text { Lack of } \\
\text { experitence bo } \\
\text { Eners } \\
\text { Modeling } \\
\text { mocesk }\end{array}$ & \\
\hline IfED Dorumentation Costs & 4000 & & & & & \\
\hline Getraperionet Cost & & 20000 & 10000 & & 8000 & \\
\hline moject re-nanutactoring & 4000 & & 2000 & 6000 & & TOTAL. \\
\hline Total & 1000 & 24000 & 18000 & 6000 & 8000 & S4300: \\
\hline \multicolumn{7}{|c|}{ cost AKAL Tsas findirest Couta } \\
\hline Prolect re-nanubcturine & & & & 3500 & $\$ 900$ & \\
\hline Getra perionet coit & & & 0 & & & \\
\hline Catra travels, meetings, etc. & 500 & & 500 & 1000 & 500 & TOTAL. \\
\hline Tots & 500 & 0 & 500 & 4500 & 4500 & 10000 \\
\hline
\end{tabular}


didn't understand the role of the Commissioning Authority and in spite of the multiple suggestions of the LEED AP the design was carried out without the CxA help. The CxA was contracted right before the final approval of the project and had the time to summarily analyze the project spotting gaps in the project design and documentation. Such problems were then corrected before the final project approval and therefore avoiding change orders during construction phase but still the project had to be partially modified and CXA related documents such as OPR and BOD had to be re-defined. The cost of this re-manufacturing activity was of 8.500 Euros.

- No appropriate clauses in bid documentation. All professional fees related to design services were determined as percentages of the whole project cost. However, no specific clause was introduced in order to fix the prices of services which were then fluctuating on the basis of the construction cost. The lack of a project management services reviewing the whole project along with the lack of experience of the public owner in managing such projects caused major delays in the process which led to higher construction costs. Therefore also the costs of sustainability-related activities rose for a total amount of $14.000 €$

- Systematic cuts to budget due to change-orders and delays. The huge delay of the project brought to price increase and big deficits in the project budget which involved also the sustainability-related aspect. The total cost for the design change orders was 60.000 Euros of which 6.000 were related to sustainability features which also suffered a reduction of 3 LEED points due to this problem.

- Lack of knowledge about energy modelling role and process. The original design bid called for a school complex certified under the LEED for Schools 2007 protocol with all expenses for related services included. Energy modeling was also included and the designer tried to develop it but after several attempts realized that they weren't able to. An external energy modeler was then contracted by the public administration at the last minute after the final project approval. This proble led to a direct extra cost of the energy modeler of 8.000, an indirect cost for the designer of 4.500 and a loss of 5 LEED points under the credit EA 1.

- Lack of project manager supervising the whole project. A project manager for sustainability-related and LEED-related issues was contracted from the beginning but no general project manager was overviewing the whole process. This gap, along with the reduced expe- rience of the owner in managing projects of this magnitude led to several issues. First of all some managerial decisions increased the complexity of the process and then its costs, also for green-building activities. The choice of getting a whole commission to evaluate the green-building features of the design proposals instead of one single expert led to a delay of 5 months and to an additional cost of 10.000 Euros. Secondly the lack of coordination with the homeland technical services led to several project re-manufacturing activities that only for sustainability-related activity cost 8.000 Euros. Finally and most important, the delay of the whole process caused by the lack of a general managing entity and slow bureaucracy processes became so huge that the whole certification process is in danger. The design begun in 2008, finished in 2014 and currently in 2016 the construction has not started yet. The final deadline to complete the LEED certification process will be June 2019 and if the school complex won't be done by then the whole LEED process will vanish.

\section{CONCLUSIONS}

The present work allowed researchers to identify the main problems occurred during the project design phase development related to green-building practices of one single case-study project. Problems were classified in five different categories which caused three different types of losses, or "waste", as defined under the LEAN philosophy [13] (J. Liker 2003): cost, time and sustainability features.

From the cost point of view sustainability-related problems accounted for 64.000 Euros that represent the $26,5 \%$ of the initial project budget for the design, 240,767 Euros.

From the scheduling point of view the project suffered a delay of 165 working days due to unforeseen project management problems only for sustainability-related activities. The delay was calculated on the basis of the rigid scheduling principles cited in chapter 4 [16] (Harris, R.B. - 1978) considering the bar chart critical path. However, the magnitude of the overall project delays caused by lack of owner's experience and bureaucracy moves this green-building issue to the background. In fact, the whole design process suffered an overall delay of more than 3 years for the reasons cited above and the duration of bureaucracy-related activities cannot always be estimate in advance because in some cases are not standardized processes. Duration of political decisions, productivity of public entities relying on several public offices and internal decision processes of public administrations couldn't be estimate by researchers. Finally researchers conclude that 
theoretically the project suffered a delay of 165 working days caused by sustainability-related activities but this delay shouldn't be considered as an extension of the bar chart critical path because it interacts with too many non-standardized processes that caused a delay of a higher magnitude.

From the sustainability point of view 10 LEED points were not achieved due to the problems identified hereby which represents the $12 \%$ of the total 79 possible points identified at the beginning of the process. This result highlights the mutual dependency between project management and green-building project features. In fact, not only the introduction of green-building features affects the cost and scheduling of the design stage from the project management perspective but also the accuracy of the project management tasks affect the green-building features of the final building design.

Table reported in Figure 5 summarizes all main data resulting from the present research work.

Figure 5 -: table summarizing the project wastes occurred during the design process in terms of time, direct costs, indirect costs and green-building values.

\begin{tabular}{|c|c|c|c|c|c|c|}
\hline \multicolumn{7}{|c|}{ RESEARCH SUMMARY TABLE } \\
\hline PRCELEM CATEGOPEE & $\begin{array}{c}\text { Commissioning } \\
\text { Authoritytarks } \\
\text { \& process }\end{array}$ & $\begin{array}{l}\text { No appropriate } \\
\text { clauses in bid } \\
\text { documentation }\end{array}$ & $\begin{array}{l}\text { Lack of project } \\
\text { manager for } \\
\text { whole project }\end{array}$ & $\begin{array}{c}\text { Systematic cuts } \\
\text { to project } \\
\text { budget }\end{array}$ & $\begin{array}{c}\text { Enerzy } \\
\text { Modelling role } \\
\text { and process }\end{array}$ & TOTAL \\
\hline Additional Time (Days) & 9 & 5 & 128 & 23 & 0 & 165 \\
\hline Indirect Additional Costs $(C)$ & 500 & 0 & 500 & 4500 & 4500 & 10000 \\
\hline Direct Additional Costs (C) & 8000 & 14000 & 18000 & 6000 & 8000 & 54000 \\
\hline Green Value [LECD points] & 1 & 1 & 0 & 3 & 5 & 10 \\
\hline
\end{tabular}

Fonte - Autors

\section{LIMITATIONS}

-Time analysis: The research project had many subjects involved and no global coordination, the lack of a common protocol for the collection and storage of research-related data established prior to the project start determined a quantitative level of uncertainty.

-Estimating the delay of single activities resulted sometimes difficult and ambiguous because depended from other activities which dependency could not be calculated. By matching data proceeding from interviews and project documentation, researchers determined the duration, floats, predecessors and successors of each activity.
However, in some cases, the bureaucratic and management process was so complicated that none of the subjects involved knew what depended on what. Therefore, for the purpose of this research activities with undefined scheduling features were considered not individually but as part of groups of activities (milestones) whose start and ending point could be determined univocally.

- Cost Analysis: Indirect costs resulted difficult to estimate because were not related to any written document nor any specific activity or event of the project. Furthermore, data related to indirect costs were collected through interviews to all subjects involved which, in some cases, weren't able to identify project management wastes.

- Researchers only analyzed the cost of the problems they had related information of, there might have been other extra costs that couldn't be estimate because nobody appointed them as problems and so researchers didn't even know the existence of.

- Finally, researchers could not estimate the cost of not using the money allocated for the project during a medium-large period of time. The case-study refers to a public project funded by the public authority. Funds for the project construction have to be listed and approved along with the public county budget still during the project design stage and remain locked in the public budget until the construction phase. Delays in design phase completion and consequently construction phase start represent a loss for the founding entity which can't use nor invest the money allocated for the entire project.

- Sustainability Analysis: For the purpose of the present work researchers took into consideration only a single green-building protocol, LEED. The need of reducing the number of variables imposed the selection of a single protocol which is currently the most used at an international 
level for number of certified buildings and square meters. However, this protocol represents only a fraction of the green-building construction market and therefore results of the present research have to be considered partially valid.

Finally, as a general limitation for the work, researchers specify that avoiding the causes that determined the problems mentioned above is a necessary condition but maybe not sufficient to avoid the waste. The problems listed above have been calculated with reference to an optimum and ideal situation characterized by zero waste in terms of time, costs and sustainability. Researchers don't have evidence that such waste can be fully avoided. In order to validate this thesis, researchers would need to analyze other projects where appropriate means and resources are implemented in order to prevent wastes listed above. This, along with other ideas listed below, represents one possible field for the development of future research works.

\section{REFERENCE LIST}

1. P.HANSFORD, D.BOWER, M. CLARE ET AL.; Executive Summary - Construction 2025; HM Government Official Document; Crown Editor; 2013.

2. HORMAN M., RILEY D., LAPINSKI A., ET AL.; Delivering Green Buildings - Process Improvements for Sustainable Construction; Journal of Green Building; 2006.

3. KLOTZ L., JOHNSON P., LEOPARD T., MARUSZEWSKI S., HROMANN M., RILEY D.; Campus Construction as a Research Laboratory: A Model for Intra-Campus Collaboration; Journal of Professional Issues in Engineering Education and Practice, Vol. 135, No. 4; October 2009.

4. LAPINSKI A., HORMAN M., RILEY D.; LEAN Processes for Sustainable Project Delivery; Journal of Construction Engineering and Management, 2006.

5. KORKMAZ ET AL.; High-Performance Green Building Design Process Modeling and Integrated Use of Visualization Tools; Journal of Architectural Engineering; 2010.

6. SYLVAIN LENFLE; Exploration and Project Management; International Journal of Project Management; 2008.

7. HAROLD KERZER; Project Management, a systems approach to planning, scheduling and controlling; 11th Edition; 2013.
8. RUSSELL-SMITH S. V., LEPECH M. D., FRUCHTER R., LITTMAN A.; Impact of progressive sustainable target value assessment on building design decisions; Building and Environment, Volume 85; February 2015.

9. LOPEZ R., SANCHEZ F.; Sustainability in construction projects: analysis of a building with two sustainable assessment tool; Proceedings from the 13th International Congress on Project Engineering, Badajoz, 2010.

10. ENACHE-POMMER E., HORMAN M.; Key Processes in the Building Delivery of Green Hospitals; Proceeding from the Construction Research Congress 2009.

11. DANIEL CASTRO-LACOUTURE, JORGE A. SEFAIR, LAURA FLÓREZ, ANDRÉS L. MEDAGLIA; Optimization model for the selection of materials using a LEED-based green building rating system in Colombia; Building and Environment, Volume 44, Issue 6; June 2009

12. GAY S., MOORE S.; Sustainable Architecture - Cultures and Natures in Europe and North America; Spon Press; 2005.

13. JEFFREY LIKER; The Toyota Way: 14 Management Principles from the World's Greatest Manufacturer; 3rd edition; McGraw-Hill Education; 2003.

14. WHELTON M., BALLARD G.; Wicked Problems in Project Definition; Proceedings of the International Group for Lean Construction 10th Annual Conference, Brazil; August 2002.

15. II SOLE 24 ORE; Business Magazine; National Salary Survey; April 2015.

16. HARRIS R.B.; Precedence and Arrow Networking Techniques for Construction, John Wiley and Sons; John Wiley \& Sons Inc; 1978.

17. ENACHE-POMMER ET AL.; $\mathbf{A}$ unified process approach to healthcare project delivery: Synergies between greening strategies, lean principles and BIM; Conference Proceeding Paper - Construction Research Congress; 2010.

18. BENAVIDES E.M.; Advanced engineering design: An integrated approach; Woodhead Publishing; 2011. 
19. BALLARD G., HOWELL G; Competing Construction

Management Paradigms; Lean Construction Journal; 2004.

20. KRIPPENDORFF KLAUS; Content Analysis: An Introduction to its Methodology; Sage Publications; 1990.

21. BALLARD G., ZABELLE T.R.; Lean Design: Process, Tools, \& Techniques; Lean Construction Institute White Paper; 2000.

22. LUO ET AL.; Lean Principles for Prefabrication in Green Design-Build (GDB) Projects; 13th Conference of the International Group for Lean Construction; 2005.

23. PETER DAHL, MICHAEL HORMAN, DAVID RILEY; Lean Principles to Inject Operations Knowledge into Design; 13th Annual Conference of IGLC, Sydney; July 2005.

24. BERTSELEN S., KOSKELA L.; Managing The Three Aspects Of Production In Construction; 10th Conference of the International Group for Lean Construction, Brazil; 2002.

25. JOHN E. TAYLOR, CARRIE STURTS DOSSICK, MICHAEL GARVIN;Meeting the Burden of Proof with Case-Study Research; Journal of Construction Engineering and Management, Vol. 137, No. 4; April 2011.

26. SALEM O., SOLOMON J., GENAIDY A., LAUGRING M.; Site Implementation and Assessment of Lean Construction Techniques; Lean Construction Journal, volume 2, issue 2; 2005.

27. EL-HALWAGI, M.M.; Sustainable Design Through Process Integration; Elsevier Inc.; 2012.

28. DAVID RILEY, AMU GROMMES, CORINE THATCHER; Teaching Sustainability in Building Design and Engineering; Journal of Green Building; 2007.

29. MASTROIANNU R. ABDELHAMID T.; The Challenge: The Impetus For Change To Lean Project Delivery; 11th Annual Conference for Lean Construction, Blacksburg, Virginia; 2003.

30. MATT STEVENS; The Construction MBA; 1st Edition; McGraw Hill; 2012.
31. KIMBERLY A. NEUENDORF; The Content Analysis Guidebook; 2nd Edition; Sage Publications, California; 2002.

32. GREG KATS; The Costs and Financial Benefits of Green Buildings; Report to California's Sustainable Building Task Force; 2003.

33. KOSKELA L., HOWELL G., BALLARD G., TOMMELEIN I.; The Foundations of Lean Construction - Design and Construction, Building in Value; 